\title{
CHANGES IN CATECHOLAMINE LEVELS DURING SHOCK IN MAN ${ }^{\circ}$
}

\author{
M. Hanquet, M.D., A. Cession-Fossion, M.D., AND J. Lecomte, M.D.
}

Traditional concepts about shock have been largely modified by the recent experimental work in this field. New light has been thrown on this syndrome, with the result that shock is no longer identified with collapse. Its diagnosis is no longer merely implied from systemic arterial hypotension, even if many authors agree that severe hypotension is a cardinal sign of shock, and even though hypotension, according to Archibald and MacLean, is still considered by many a causative factor in shock. ${ }^{1}$

Either cardiogenic, neurogenic, haemorrhagic, or septic in nature, shock nowadays appears as a "final common pathway." The purpose of this defence reaction is to protect by any means coronary circulation and principally brain irrigation, even to the detriment of some other body functions. ${ }^{2}$ Its cause is a particular state of circulatory distress which requires an adaptation of the vascular bed to its reduced content. The normal cross section of the vascular bed shrinks to face new priorities; the reduced cardiac output is then diverted to preferential circuits, mainly to brain and coronary circulations. ${ }^{3}$ In this situation, a sluggish peripheral circulation leads to a well-known clinical picture: the skin is pale, cold, and cyanotic; urine output is scant; respiration is disturbed; and finally, arterial blood pressure undergoes miscellaneous changes, the most usual variation being a narrowing of the pulse pressure.

Different phenomena may induce major disturbances in the evolution of shock. (a) Ischaemia of the skin and muscles may lead to metabolic acidosis. (b) Ischaemia of the gastrointestinal tract may cause the reabsorption of bacterial toxins, which enter the portal system. (c) Circulatory disturbances in the liver result in metabolic alterations; moreover, this organ can no longer function as a barrier to intestinal toxins. (d) Finally, renal function is reduced, and sometimes anuria becomes a threat.

The mechanism underlying this condition is essentially a vasoconstriction in all these tissues; this vasoconstriction principally affects those vessels supplied with alpha-adrenergic receptors. These are stimulated by the catecholamines liberally secreted by the adrenal medulla and the sympathetic endings, in response to the initial state of circulatory distress. ${ }^{4}$

These events occur in two successive stages, called by some authors reversible and irreversible shock. ${ }^{5,6}$ During the first stage, vasoconstriction narrows the precapillary arterial and post-capillary venular sphincters throughout a wide vascular territory which thus becomes isolated from central circulation. The cardiac output, so diverted from most of its regular circuits, remains adequate to meet myocardial and cerebral perfusion. The systolic arterial pressure is well maintained in central vessels, but the diastolic pressure increases, leading to a

'Translated by Dr. R. Déry, Quebec, P.2. 
narrowing of the pulse pressure. Peripheral tissue perfusion soon becomes inadequate. Conditions are set for the occurrence of metabolic acidosis and for functional disturbances in the liver, the intestinal tract, and especially the kidney. Then the second stage begins, in which the pre-capillary arterial sphincters open, while the post-capillary venous sphincters remain closed. Owing to this new pattern in the microcirculation, large amounts of blood begin to pool in the isolated capillary bed. Capillary hydrostatic pressure rises to values which exceed colloid osmotic pressure, so that abundance of plasma diffuses towards interstitial spaces. The precarious blood volume which could previously support an adequate systolic pressure in central vessels is thus suddenly decreased, first by blood sequestration in dilated capillaries, then by plasma leaking into interstitial tissues. This results in a generalized circulatory collapse which may lead to irreversible shock and death.

The difference between the peculiar response of pre-capillary and post-capillary sphincters has received various interpretations. Among these, the most widely accepted is the fact that pre-capillary arterial sphincters are more sensitive to acidosis than post-capillary ones, and accordingly become less and less responsive to catecholamines.

In view of these considerations of the function of catecholamines in the microcirculation, we decided to measure adrenaline (A) and noradrenaline (N) levels during shock states in men. We thus measured circulating catecholamines in wounded men with severe shock, and we compared the results with those of normal individuals. In the same way, we measured the adrenal catecholamines in wounded men who died in shock, and compared the results thus obtained with those found in the adrenals of individuals without shock.

\section{Techniques}

\section{Measurement of blood catecholamines}

In normal subjects. Twenty millilitres of blood were sampled from 21 normal adults under ambulatory hospital treatment. In order to prevent catecholamine auto-oxidation, $0.5 \mathrm{ml}$. of a 0.02 per cent solution of ascorbic acid was immediately added to the blood sample. After centrifuging, plasma was collected and the haematocrit was measured. Determination of plasma amines was performed following the fluorometric method of von Euler and Lishajko; ${ }^{7}$ plasma was passed, along with EDTA, on an alumine column at a $\mathrm{pH}$ of 8.4; catecholamines were then eluted with $0.25 \mathrm{~N}$ acetic acid. They were oxidized with $\mathrm{K}_{3} \mathrm{Fe}(\mathrm{CN})_{6}$ and converted into fluorescent lutines with a mixture of $\mathrm{NaOH}$ and ascorbic acid. Measurements were obtained with a Zeiss spectrofluorimeter.

In subjects in shock. Determinations were the same as those in normal subjects. Blood samples were obtained in 14 patients from the Centre de réanimation du Service de Chirurgie de l'Hôpital de Bavière; these patients were under treatment for various diseases, most often for trauma, and every one was in a clinically evident shock state. Serial samples were obtained in the same patient, up to, whenever possible, the end of the clinical shock syndrome. 
Measurement of catecholamines in the adrenal medulla

In normal adrenal glands. Adrenal glands were obtained in patients with obliterative arteriopatries; if we except this particular disease, every patient in this group enjoyed a normal cardiovascular function and was undergoing a therapeutic adrenalectomy under general anaesthesia. As soon as removed, the adrenals were carefully cleaned, weighed, and pounded in 5 per cent trichloracetic acid. Their catecholamine content was determined by spectrofluorometry following von Euler's and Lishajko's technique.?

In the adrenals of patients in shock. Adrenal glands were obtained immediately after the death of individuals who died in shock. They were processed as previously mentioned.

\section{Blood catecholamines}

\section{Results and Discussion}

Table I shows the values of blood catecholamines expressed in $\mu \mathrm{g} / \mathrm{L}$ of blood, in normal individuals. Noradrenaline content was always higher than the adrenaline, and generally (in 16 cases out of 21 ) the sum of both catecholamines remained below $4 \mu \mathrm{g} / \mathrm{L}$.

Table II illustrates, besides the results of catecholamine determinations in the patients in shock, the causes of shock, age of the patients, their cardiovascular state, and their hourly urine output. In these fourteen patients, the following clinical pictures were found: five post-traumatic effusions of blood into the peritoneal cavity, from rupture of the liver, the spleen or a hollow viscus, five retroperitoneal haemorrhages from pelvic fractures, one severe haemorrhage from external trauma, one haemorrhage from gastric origin, one skull fracture with severe neurovegetative reactions, one septic shock.

These patients showed signs of severe shock, with intense vasoconstriction and frequently with skin lividity. In ten cases, hourly urine output fell below $50 \mathrm{ml}$ during the syndrome, while arterial blood pressure decreased below 100 $\mathrm{mm} \mathrm{Hg}$ in only five. Every patient in this group received the best treatment required by his clinical condition; they were given perfusions, and, if necessary, blood transfusions. No vasopressors were administered.

Plasma catecholamine values were found to vary considerably from patient to patient. In five patients out of the fourteen included in this study, plasma epinephrine was higher than $3.97 \mu \mathrm{g} / \mathrm{L}$, which is the highest value obtained in our normal controls (mean of the controls: $1.58 \mu \mathrm{g} / \mathrm{L}$ ). Norepinephrine values averaged $2.35 \mu \mathrm{g} / \mathrm{L}$ in the controls, the highest figure reaching 4.80 in one individual. This last value was exceeded in six out of fourteen patients in shock.

Moreover, the mean results obtained in our whole experiment clearly disclosed higher plasma catecholamines in the shocked patients as compared with the controls. During shock, mean results for adrenaline were $3.30 \mu \mathrm{g} / \mathrm{L}$, for noradrenaline $7.34 \mu \mathrm{g} / \mathrm{L}$, and for total catecholamines (A + NA) $10.64 \mu \mathrm{g} / \mathrm{L}$; while in our controls, adrenaline remained within normal limits at $1.58 \mu \mathrm{g} / \mathrm{L}$, noradrenaline at $2.35 \mu \mathrm{g} / \mathrm{L}$, and total catecholamines at $3.93 \mu \mathrm{g} / \mathrm{L}$.

Thus an increased catecholamine release occurs during shock, giving evidence of an intense and prolonged stimulation of the orthosympathetic system. 
Seemingly, this stimulation does not refer only to the adrenal medulla, but to the whole peripheral adrenergic system, which is intensely excited, as indicated by high plasma catecholamine levels.

This hypercatecholaminaemia disappears on recovery from shock. Six hours after their recovery from shock, three patients out of 14 displayed a mean plasma adrenaline of $0.91 \mu \mathrm{g} / \mathrm{L}$ (controls: $1.58 \mu \mathrm{g} / \mathrm{L}$ ); noradrenaline was as low as $2.17 \mu \mathrm{g} / \mathrm{L}$, as compared with $2.35 \mu \mathrm{g} / \mathrm{L}$ in the controls; total catecholamines amounted to $3.08 \mu \mathrm{g} / \mathrm{L}(3.93 \mu \mathrm{g} / \mathrm{L}$ in normal controls $)$.

The relationship between hypercatecholaminaemia and arterial hypotension was far from evident. Let us consider the five cases (nos. 3, 5, 9, 11, and 12) in which we found a total catecholamine levels higher than $8 \mu \mathrm{g} / \mathrm{L}$. This is twice the mean result in our controls. In these patients, only three (nos. 5, 9, and 11) displayed a systolic arterial pressure below $90 \mathrm{~mm} \mathrm{Hg}$ during recovery from shock; in contrast, patients 3 and 12 had systolic arterial pressure above 110 $\mathrm{mm} \mathrm{Hg}$.

On the other hand, a severe reduction in urinary output was seen with the highest catecholamine levels. Actually, patients 5 and 9 , who exhibited the highest catecholamines $(58.05$ and $15.11 \mu \mathrm{g} / \mathrm{L})$ developed overt anuria during their recovery from shock.

\section{Adrenal gland catecholamines}

The intense stimulation of the adrenal medulla during shock is well demonstrated by our comparative studies of these glands both in the normal individual and in patients who died in shock. Table III illustrates our results.

In the group of adrenal glands from normal individuals we observed catecholamine contents of $6.95 \mu \mathrm{g} / 10 \mathrm{mg}$ for adrenaline, $3.76 \mu \mathrm{g} / 10 \mathrm{mg}$ for noradrenaline, and $8.54 \mu \mathrm{g} / 10 \mathrm{mg}$ for total catecholamines. It is interesting to note that the corresponding values from the adrenals of patients in shock were 2.35, 2.23, and $4.48 \mu \mathrm{g} / 10 \mathrm{mg}$ of tissue. Shock induces a stimulation which places a very high demand upon the adrenal medulla. There is not enough time for synthesis to counterbalance the large amount of catecholamines freely discharged from the adrenal tissue.

However, the low level of adrenal catecholamines observed in the patients who died in shock remains seemingly sufficient to meet casual needs. Likewise, as demonstrated by Hardaway, ${ }^{8}$ plasma catecholamines never fall to inadequate levels during shock.

\section{Conclusion}

These results demonstrate the magnitude of the adrenergic stimulation during shock in man. Such stimulation leads to a rise in plasma catecholamines and to a relative impoverishment of the catecholamine stores in the adrenal medulla. The clinical effectiveness of this stimulation is, however, not evident in every case. From a clinical point of view, the state of shock and the subsequent hypercatecholaminaemia are not necessarily related to a severe decrease in the arterial blood pressure. On the other hand, a reduction in the urine output goes with the highest plasma catecholamine levels. 


\section{BIBLIOGRAPHIE}

1. Archibald, E. W. \& MacLean, W. S. Observations upon Shock with Particular Reference to the Condition as seen in War Surgery. Ann. Surg. 66: 280 (1917).

2. Nickerson, M. Shock and Circulatory Homeostasis. New York: Josiah Maccy Jr. Foundation (1965).

3. GregG, D. E. Hemodynamic Factors of Shock. In Shock: Pathogenesis and Therapy. Springer Verlag (1962), p. 52.

4. Hokfelt, B.; Bygdeman, S.; \& Sexkenes, J. The Participation of the Adrenal Glands in Endotoxin Shock. In Shock: Pathogenesis and Therapy. Springer Verlag (1962), p. 151.

5. LILLehei, R. C.; Longerbeam, J. K.; \& Rosengerg, J. C. The Nature of Irreversible Shock. In Shock: Pathogenesis and Therapy. Springer Verlag (1962), p. 106.

6. LILleheI, R. C.; LongerbeaM, J. K.; Bloch, J. H.; \& MANaw, W. G. The Nature of Irreversible Shock: Experimental and Clinical Observations. Ann. Surg. 160: 682 (1964).

7. von Eurer, U. S. \& Lishajko. Improved Technic for the Fluorimetric Estimation of Catecholamines. Acta Physiol. Scandinav. 51: 348 (1961).

8. Hardaway, R. M. Clinical Management of Shock. Springfield: Charles C. Thomas (1968). 